\title{
Vibroprotection System with the Elastic Element and the Electrically Controlled Damping
}

\author{
Evguenia KOROBKO*, Vladzimir KUZMIN*, Algimatas BUBULIS**, Viachaslau BILYK*, \\ Ekatherina NOVIK*, Kazimieras JUZE்NAS** \\ *Heat and Mass Transfer Institute of NAS Belarus, 15 P. Brovka str., 220072 Minsk, Belarus, \\ E-mail: evkorobko@gmail.com \\ **Kaunas University of Technology, 73 Donelaicio str., 44239, Kaunas, Lithuania \\ cross $^{\text {ref }}$ http://dx.doi.org/10.5755/j01.mech.24.5.21070
}

\section{Introduction}

Reduction of vibrations may be performed using different methods, depending on the desired dynamic behavior: damping, isolation or stiffening of mechanical systems. It is known that it is possible to create controlled vibration protection systems using liquid-dispersed materials that change their damping characteristics as a result of changes in the internal structural interactions of the particles of the disperse phase under the influence of an external electric or magnetic field [1-6]. The designs of damping devices for the vibration control and protection systems are actively being developed. Applications of materials with controllable properties enables development of semi-active vibrations control systems. Those devices may work in the modes of pressure flow, shear, compression or combined mode [313]. Recently researchers of different countries are developing new compositions of electrically controlled damping materials (ECDM). The use of ECDM in vibroisolation elements (fluid-flow dampers) of various vibroprotection systems can significantly reduce the amplitude of forced oscillations of the protected object and the decay time of its free oscillations. Vibrations control is performed by changing the viscoplasticity of the working fluid in the damper channel for oscillatory systems containing both elastic elements and dampers. As a rule, the damping of oscillations is effective in the direction of the action of an external shear force in the perpendicular direction to the external electric field strength vector [6-11], which does not allow the same effect on simultaneous oscillations in other directions.

The aim of this work is the development of damping devise with the elastic element of dual purpose (enabling damping of vibrations in two directions) and experimental investigation of its application in a single-mass oscillatory system.

\section{Setup for experiments}

A single-mass scheme with an elastic element controlled by an external electric field was chosen as an oscillation system.

The scheme of an experimental "sky hook" system with the elastic element of composite construction "double flat spring" and with electric field controlled stiffness is shown in the Figure 1. The elastic "double flat spring" element is composed of two coaxial-cylindrical flat springs, serving as electrodes. The gap between spring elements may be filled with ECDM. Each flat spring has thickness of 1 $\mathrm{mm}$ and is made of aluminum alloy. The outer diameter of springs is $55 \mathrm{~mm}$, and the inner diameter is $51 \mathrm{~mm}$, the height of the springs is $130 \mathrm{~mm}$. The surface of flat springs, facing to the inside of the gap, is covered with hard-anodized film of aluminum oxide with a thickness of approximately $20 \mu \mathrm{m}$.

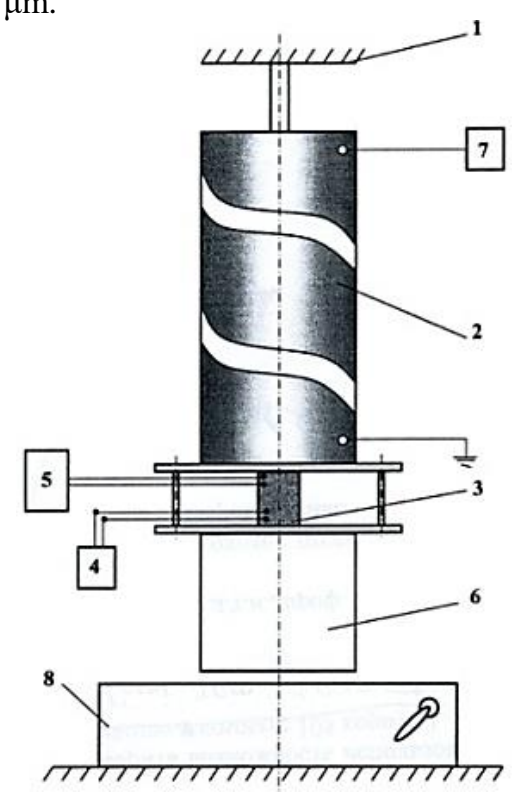

Fig. 1 Scheme of vibration protection system with the elastic "double flat spring" element: 1 is a base, 2 is an elastic element, 3 is a displacement sensor, 4 is a power supply of the displacement sensor, 5 is an oscilloscope, 6 is a mass (load), 7 is a high-voltage power supply unit, 8 is a magnetic fixture (Table)

Experiments are performed in such sequence: one end (Fig. 1) of the elastic "double flat spring" element 2 is rigidly attached to the base 1 , and the other is loaded with load of $2 \mathrm{~kg}$ in the form of a steel cylinder 6 and a displacement sensor 3 . The power supply of the displacement sensor is carried out from the power supply unit 4 , and the sensor signal is recorded with an oscilloscope. A high voltage is applied to one of the springs from the power supply unit 7 , and the other one is grounded. The contact points are carefully isolated. When the magnetic fixture 8 is turned on, the load mass is attracted to its surface and fixed. When the magnetic fixture is turned off, the load mass attached to the vibroprotection system performs vertical oscillations measured by the vertical displacement sensor.

To study the horizontal oscillations, the place of contact of the load mass with the magnetic table is horizontally displaced in a certain distance and the position of the 
load is fixed by the activation of a magnetic fixture. The free horizontal oscillations of the system are measured by the horizontal displacement sensor after turning off the magnetic fixture. Amplitudes of oscillations in the horizontal direction are recorded.

Maintaining of the thickness of the ECDM layer is possible by placing the mesh material or particles of a calibrated particle size or a dielectric layer with a high electrical resistance of materials such as polyethylene, glass or insulating ceramics between the electrodes. A calibrated dielectric stripe is used to assure the gap of $1 \mathrm{~mm}$ between springs filled with an electrically controlled damping material in the experimental setup. Fig. 2 shows the photo of the experimental setup.

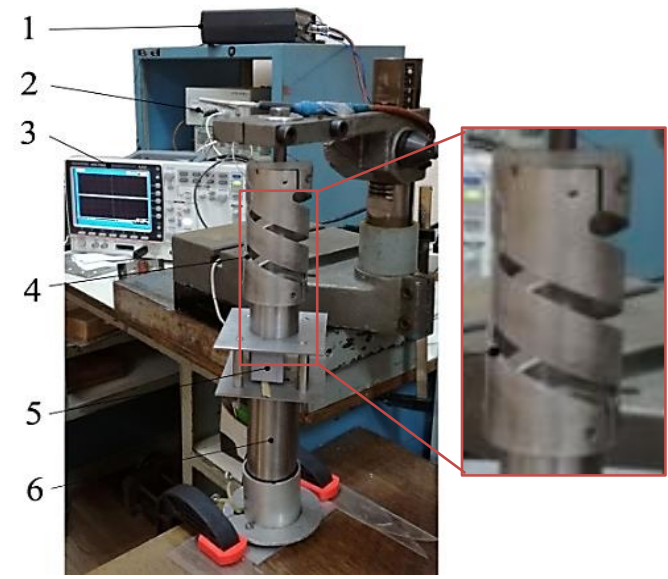

Fig. 2 Photo of the experimental setup: 1 - high-voltage power supply, 2 - power supply of the displacement sensor, 3 - oscilloscope, 4 - double flat spring elastic element with ECDM, 5 - displacement sensor, 6 mass (load)

Electro rheological slurry containing $58 \mathrm{wt} \%$ aluminum phosphate in a synthetic oil is developed as an electrically controllable damping material. The damping characteristics of a vibration protection system with an elastic element depend on the mechanical properties of the constituent electrodes, their combination, on the viscoelastic properties of the ECDM and on the magnitude of the external electric field [2].

\section{Results of experimental research}

Analysis of damping properties of electrically controlled damping material. The yield stress $\tau_{0}$ of ECDM was determined on the rheometer "Physica MCR 301" (Anton Paar) in the mode of linear growth of the shear stress. A plate-plate measuring cell with a plate radius of $12.5 \mathrm{~mm}$ and a gap between the plates of $1 \mathrm{~mm}$ in an electric field of strength $E=0 \div 2.5 \mathrm{kV} / \mathrm{mm}$ were used. The yield stress characterizes the strength of the material structure. The dependence of the yield strength of ECDM on the electric field strength is shown in the Fig. 3. Yield stress $\tau_{0}$ of ECDM reaches $1,7 \mathrm{kPa}$ in an electric field of strength $E=$ $=2.5 \mathrm{kV} / \mathrm{mm}$, which gives an increase in yield stress more than 300 times than in the absence of electric field enabling control of the material damping properties.

Complex shear modulus of the developed material $G^{*}=G^{\prime}+i G^{\prime}$. Here $G^{\prime}$ is the storage (elasticity) modulus, $G$ " is the loss modulus and $i$ is the imaginary unit [14]. The components of the complex shear modulus of ECDM $G$ ' and $G$ " were measured in the mode of sinusoidal tangential vibrations with a constant frequency $f=10 \mathrm{~Hz}$ of the upper plate and the strain amplitude in the range of $1 \cdot 10^{-5}-1 \cdot 10^{-2}$ (Fig. 4).

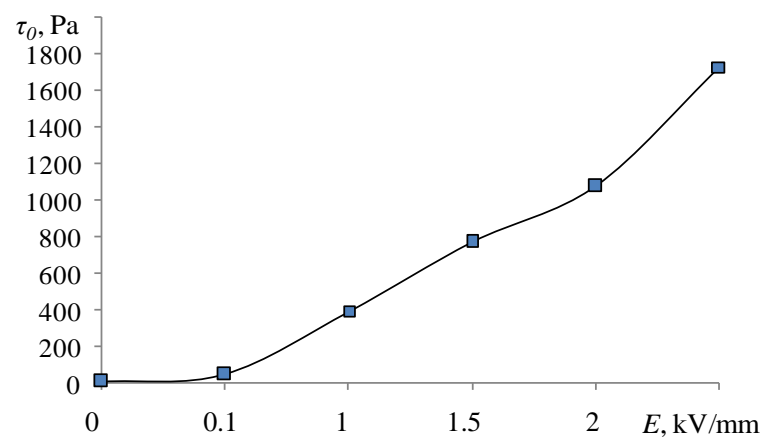

Fig. 3 Dependence of the yield stress of ECDM on strength of electric field
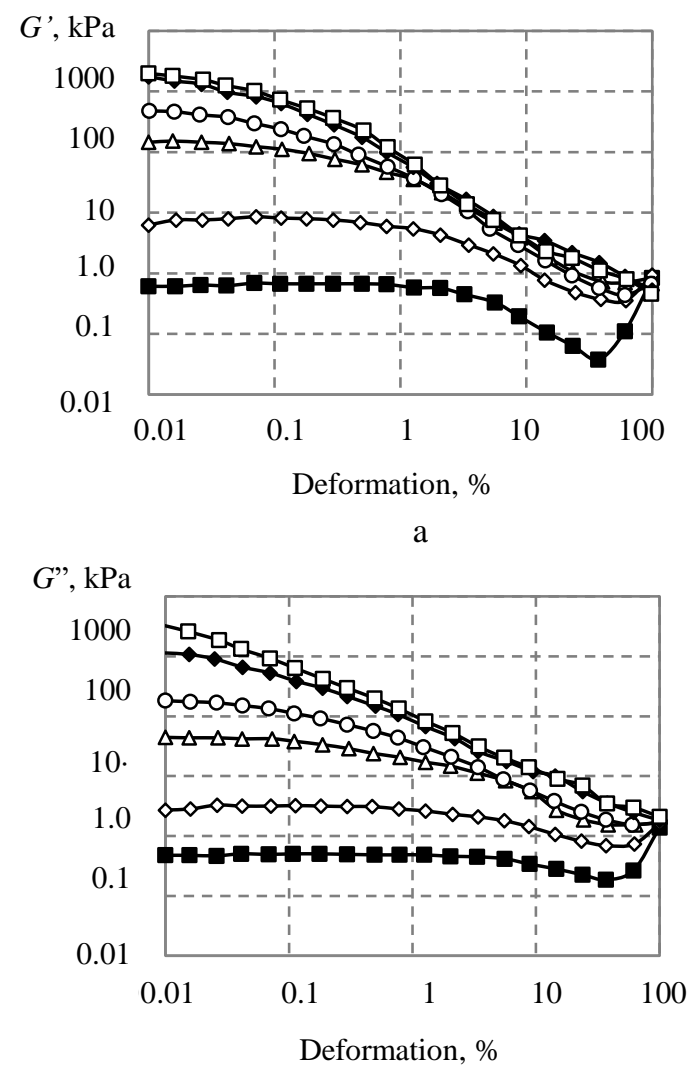

b)

$$
-\square-1,-\diamond-2,-\Delta-3,-\circ-4,-\bullet-5,-\square-6
$$

Fig. 4 Dependence of $G^{\prime}$ (a) and $G^{\prime \prime}$ (b) of ECDM at various electric field strengths: 1 is $0 \mathrm{kV} / \mathrm{mm} ; 2$ is $0.5 \mathrm{kV} / \mathrm{mm}$; 3 is $1 \mathrm{kV} / \mathrm{mm}$; 4 is $1.5 \mathrm{kV} / \mathrm{mm}$; 5 is $2 \mathrm{kV} / \mathrm{mm}$; 6 is $2.5 \mathrm{kV} / \mathrm{mm}$

Experimental testing of vibrations reduction. The natural oscillations of the mass attached to the vibration protection system with an elastic element (Fig. 2) were investigated without filling its gap with ECDM, and with filling. The frequency of the natural vibrations of the damping system with an elastic "double flat spring" element without ECDM filling was approximately $10 \mathrm{~Hz}$. 
The ECDM sample is filled into the gap of elastic element of the experimental system. Then, the influence of the electric field intensity applied to the ECDM on the amplitudes of the vertical and horizontal vibrations of the load mass attached to the vibroprotection system is determined. Fig. 5 shows the amplitude of the vertical vibration of the mass as a function of time when the strength of a constant electric field varies from 0 to $1.2 \mathrm{kV} / \mathrm{mm}$.
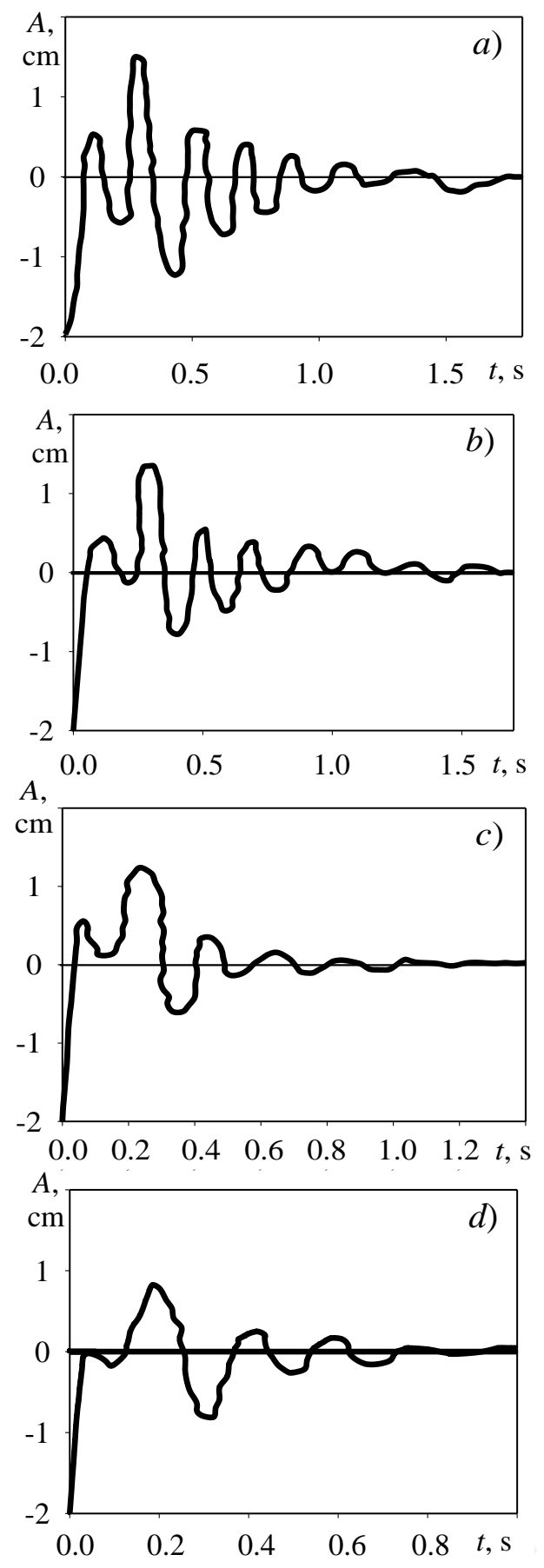

Fig. 5 Dependences of the amplitude of vertical mass oscillations versus time for different electric field strengths: a) $E=0 \mathrm{kV} / \mathrm{mm}$; b) $0.4 \mathrm{kV} / \mathrm{mm}$; c) 0.8 $\mathrm{kV} / \mathrm{mm}$; d) $1.2 \mathrm{kV} / \mathrm{mm}$

The coefficients of the logarithmic decrement of damping for the obtained dependences of the oscillation amplitude of mass of the vibroprotection system with the elastic element and ECDM versus time (Fig. 5) are calculated according to the formula:

$$
d=\ln \left(\frac{A_{n}}{A_{n+1}}\right),
$$

here: $A_{n}$ and $A_{n+1}$ are the value of the two nearest amplitude values of the measured displacement.

Fig. 6 shows the dependences of the logarithmic damping decrement and the time of total attenuation of the vertical natural oscillations on the strength of electric field.

Test results show that the logarithmic decrement of damping of the vertical natural oscillations of the load mass varies from 0.44 to 0.75 . The time of total attenuation decreases from $1.74 \mathrm{~s}$ to $0.94 \mathrm{~s}$ when the electric field strength increases from 0 to $1.2 \mathrm{kV} / \mathrm{mm}$.

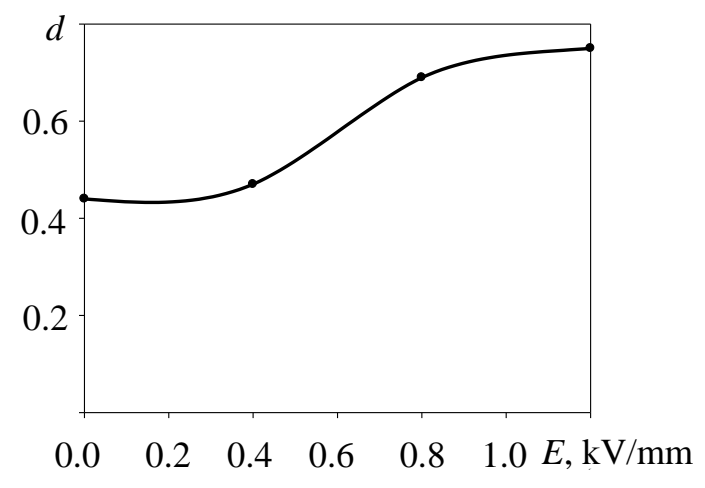

a

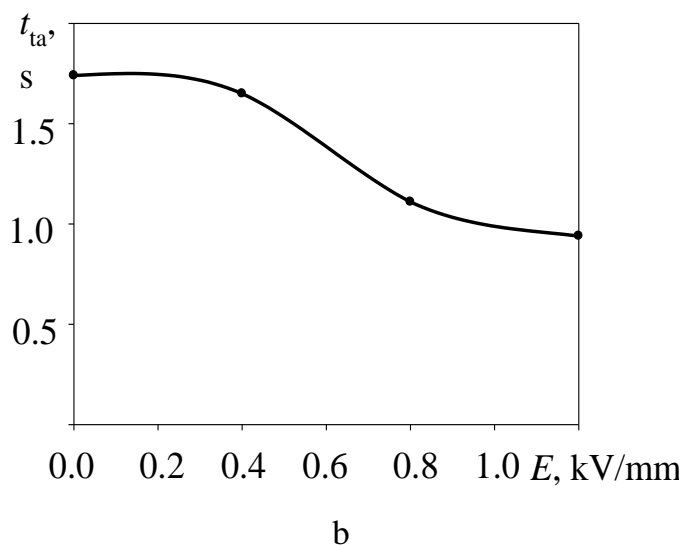

Fig. 6 Dependences of the logarithmic damping decrement $\mathrm{d}$ (a) and the time $t_{t a}$ of total attenuation of the vertical natural oscillations (b) on the electric field strength

Fig. 7 presents the results of a study of the horizontal oscillations of the load mass when a constant electric field is applied to it and the voltage varies from 0 to $1.2 \mathrm{kV} / \mathrm{mm}$.

Based on the results shown in Fig. 7, the dependences of the logarithmic damping decrement and the time of total attenuation of the horizontal natural oscillations of the mass from the strength of electric field are presented in the Fig. 8.

It can be seen in the Fig. 8 that the logarithmic decrement of the damping of horizontal natural oscillations of mass increased from 0.13 to 0.83 . The time for the total attenuation of the horizontal natural oscillations decreases from 14.2 to 5.5 seconds with a change in the electric field strength from 0 to $1.2 \mathrm{kV} / \mathrm{mm}$. 
Thus, the conducted experimental studies show the possibility of controlling the damping of the both vertical and horizontal vibrations of the mass of the vibration protection system using the dual-purpose elastic element with the developed ECDM containing $58 \mathrm{wt} \%$ aluminum phosphate in a synthetic oil.
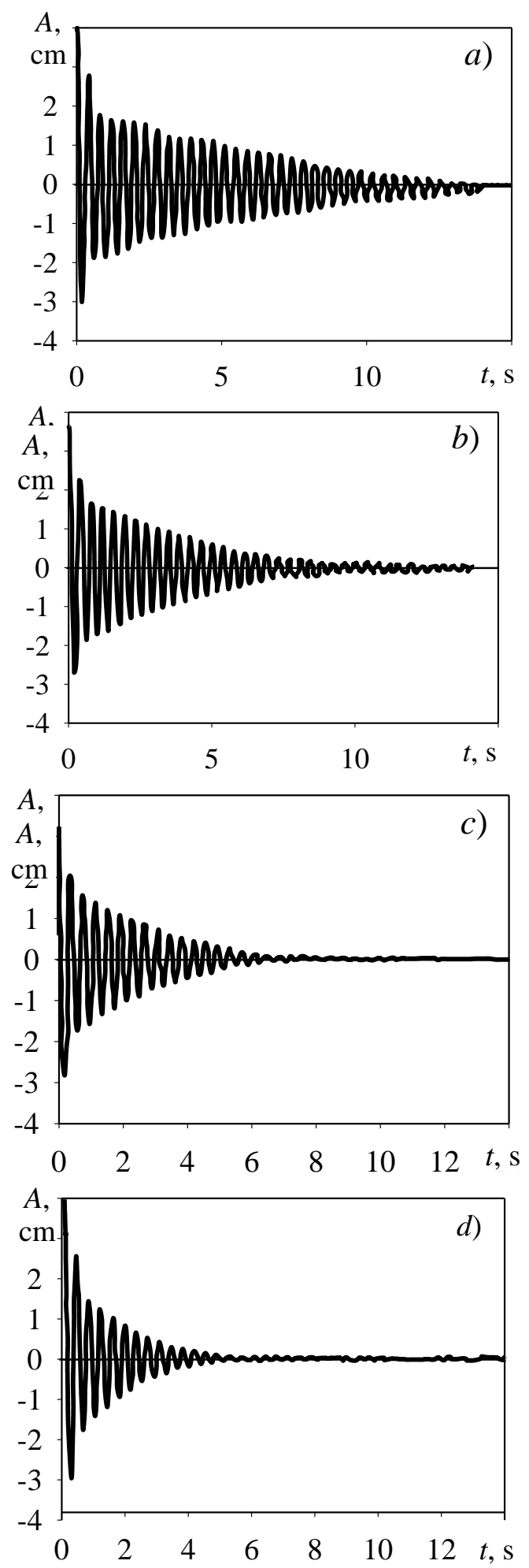

Fig. 7 Dependence of amplitude horizontal oscillations of mass on time for different values of electric field strength: a) $E=0 \mathrm{kV} / \mathrm{mm}$; b) $0.4 \mathrm{kV} / \mathrm{mm}$; c) $0 . \mathrm{kV} / \mathrm{mm}$; d) $1.2 \mathrm{kV} / \mathrm{mm}$

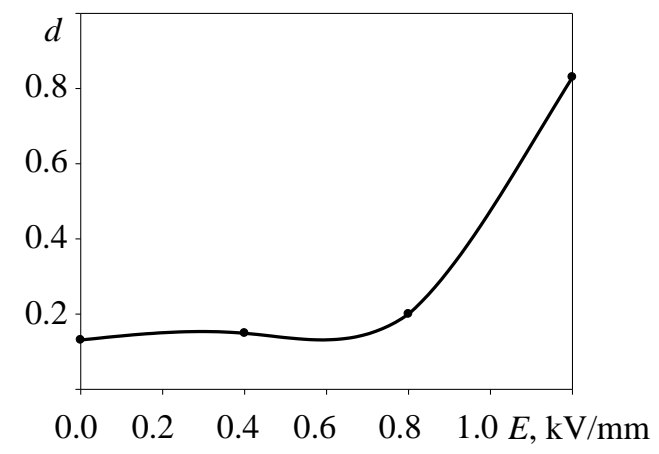

a

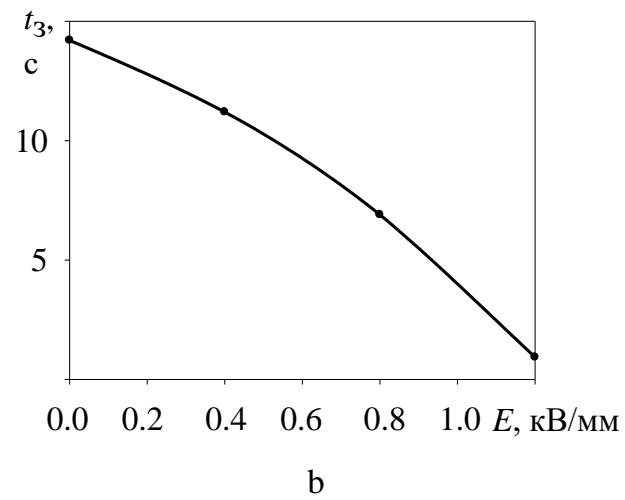

Fig. 8 Dependence of the logarithmic damping decrement $d$ (a) and the time of total attenuation $t_{t a}$ of the horizontal natural oscillations (b) on the electric field strength

This work was carried out with the financial support of Belarus State Research Program "Energy Systems, Processes and Technologies" (scientific task No. 2.46, 2016-2018).

\section{Conclusions}

The elastic element of the original design with an electrically controllable damping material was created. Vertical and horizontal natural oscillations of the load mass attached to the vibroprotection system with the elastic "double flat spring" element are studied. It is determined that the logarithmic decrement of vertical natural oscillations increased by a factor 1.7 , and the horizontal natural oscillations increased by a factor of 6.4 with the increase in the external electric field applied to the EDM from 0 to $1.2 \mathrm{kV} / \mathrm{mm}$. While time for the total attenuation of the vertical oscillations decreases by a factor of 1.9 and horizontal oscillations decreases by a factor of 2.6. The results of experimental investigation show possibility to create semi-active simultaneously controlled vibroprotection system from bi-directed external excitations.

\section{References}

1. Dixon, J. C. 2007. The Shock Absorber Handbook: Second Edition, John Wiley \& Sons, Ltd. 432 p.

2. Korobko, E. V. 1996. Electrostructured (electro-rheological) fluids: features of hydromechanics and possibilities of using, Minsk: Nauka i technika. 189 p. 
3. Bazinenkov, A. M.; Mikhailov, V. P. 2015. Active and semi active vibration isolation systems based on magnetorheological materials, Procedia Engineering 106:170174. https://doi.org/10.1016/j.proeng.2015.06.021.

4. Han, Y. M.; Oh, J. S.; Kim, S.; Choi, S. B. 2017. Design of multi-degree motion haptic mechanisms using smart fluid-based devices, Mechanics Based Design of Structures and Machines 45(1): 135-144. https://doi.org/10.1080/15397734.2015.1132629.

5. Sun, S. ; Yang, J. ; Li, W. ; Deng, H. ; Du, H. ; Alici, G. 2015. Development of a novel variable stiffness and damping magnetorheological fluid damper, Smart Materials and Structures 24: 1-10. https://doi.org/10.1088/0964-1726/24/8/085021.

6. Kandasamy, R.; Cui, F.; Townsend, N.; Foo, C.C.; Guo, J.; Shenoi, A.; Xiong, Y. 2016. A review of vibration control methods for marine offshore structures, Ocean Engineering 127: 279-297.

https://doi.org/10.1016/j.oceaneng.2016.10.001.

7. Choi, S. B.; Han, Y. M.; Song, H. J.; Sohn, J. W.; Choi, H. J. 2007. Field test on vibration control of vehicle suspension system featuring ER shock absorbers, Journal of Intelligent Material Systems and Structures 18: 1169-1174. https://doi.org/10.1177/1045389X07083133.

8. Gao, X.; Fan, G.; Chen, J.; Dong, G. 2016. Doublelayer vibration suppression bilinear system featuring electro-rheological damper with optimal damping and semi-active control, Journal of Vibroengineering 18(6): 3891-3914. https://doi.org/10.21595/jve.2016.16577.

9. Wereley, N. M. 2007. Nondimensional herschelbulkley analysis of magnetorheological and electrorheological dampers, Journal of Intelligent Material Systems and Structures 19: 257-268. https://doi.org/10.1177/1045389X07088107.

10. Yu, T.; Meng, Y.; Wen, S. 2004. Dynamic responses of zeolite-based ER fluid sheared between two concentric cylinders, Journal of Intelligent Materials Systems and Structures 15: 621-626. https://doi.org/10.1177/1045389X04042986.

11. Di, K.; Zhu, Y.; Yang, X.; Li, C. 2006. Electrorheological behavior of copper phthalocyanine-doped mesoporous $\mathrm{TiO} 2$ suspensions, Journal of Colloid and Interface Science 294: 499-503. https://doi.org/10.1016/j.jcis.2006.04.009.

12. Method and system for control of a variable force damper: patent 6,438,473 B1 US: IPC7 G06F 7/00 / D. J. Barta, O. Raynauld, O. Valee; assignee Delphi Technologies, Inc., Troy, MI (US). - № 09/821,550; filed 29.03.2001; date of patent: 20.08.2002.

13. Butz, T.; von Stryk, O. 2002. Modelling and simulation of electro- and magnetorheological fluid dampers, ZAMM - Z. Angew. Math. Mech. 82 (1): 3-20. https://doi.org/10.1002/1521-4001(200201)82:1.

14. Korobko, E.; Novikova, Z.; Zhurauski, M.; Kazak, H.; Dragašius, E. 2014. Investigation of elasticity of magnetosensitive adaptive materials for laminated composite structures, Mechanika 20(5): 466-470. https://doi.org/10.5755/j01.mech.20.5.7080.

E. Korobko, V. Kuzmin, A. Bubulis, V. Bilyk, E. Novik, K. Juzėnas

\section{VIBROPROTECTION SYSTEM WITH THE ELASTIC ELEMENT AND THE ELECTRICALLY CONTROLLED DAMPING}

S u m m a r y

The study is performed to investigate the damping characteristics of the developed vibroprotection system with the double flat spring elastic element. Damping of vertical and horizontal natural oscillations of mass is studied under the change in the external electric field applied to the electrically controllable damping material.

It is determined that the logarithmic decrement of vertical natural oscillations increased almost twofold, and the logarithmic decrement of horizontal natural oscillations increased by a factor of 6 with the change of electric field from 0 to $1.2 \mathrm{kV} / \mathrm{mm}$.

Keywords: vibrations, damping, electrically controlled damping materials.

Received June 27, 2018

Accepted October 18, 2018 